\title{
Do Changes on Sovereign Credit Rating Have Impacts on the Interdependence of Stock Markets in the Asian-Pacific Emerging Markets?
}

\author{
Bo Ni \\ College of Economics, Jinan University, Guangzhou, China \\ Email: brankol@163.com
}

How to cite this paper: Ni, B. (2017) Do Changes on Sovereign Credit Rating Have Impacts on the Interdependence of Stock Markets in the Asian-Pacific Emerging Markets? Modern Economy, 8, 351-367. https://doi.org/10.4236/me.2017.83025

Received: January 9, 2017

Accepted: March 3, 2017

Published: March 6, 2017

Copyright $\odot 2017$ by author and Scientific Research Publishing Inc. This work is licensed under the Creative Commons Attribution International License (CC BY 4.0)

http://creativecommons.org/licenses/by/4.0/

c) (i) Open Access

\begin{abstract}
This paper investigates the asymmetric effects of upgrade and downgrade of the sovereign credit rating on regional interdependence of seven emerging stock markets in the Asian Pacific Area. Firstly, by comparing the crosscountry correlation matrices of stock market index returns on event days and none event days, we find out increases in correlations in both upgrade and downgrade rating days but the frequency of decreasing correlations is significantly higher in downgrade rating days. Secondly, with a regression analysis taking advantage of time-varying conditional correlations of each stock market index with regional market index, we discover a significant increase in the correlations of most countries because of the common information effect triggered by the upgrade rating events, while for the downgrade rating events, dominant differential information effect results in decrease in the correlations. Moreover, in terms of effects of changes on sovereign ratings from other regional countries, downgrade rating events are more influential. Lastly, we apply an Error Correction Model and discern a significant long-run effect caused by the changes on the sovereign credit ratings and significant shortrun transitory effect only exists in the Thailand stock market, the source of Asian Financial Crisis, which supports the financial contagion theory.
\end{abstract}

\section{Keywords}

Sovereign Credit Ratings, Asian-Pacific Emerging Markets, Interdependence of Stock Markets, Dynamic Conditional Correlations

\section{Introduction}

Reinforced global economic integration and even economic regionalization not only boost international trades but offer investors a chance of allocating their 
assets in foreign financial markets. However, trends of financial integration and regionalization are blamed by several scholars as the source of destabilization of global financial market. Calvo and Mendoza [1] argue that investors tend to overlook economic fundamentals in invested foreign countries and asymmetric information leads to deteriorating herding behaviors. On the other hand, Chan et al. [2] investigate investments of mutual funds on 26 developed and developing countries and discover that home bias that share of investments in their home countries always exceeds that in foreign markets is prevalent in their allocations of assets. Moreover, they point out that increased familiarities such as close geographically locations, using same common language, cultural proximity and frequent bilateral trades will solve the information asymmetry and influence the home bias. Thus, in order to reduce sunk costs caused by information asymmetry, international portfolio investors prone to assign their wealth among regional markets.

On the other hand, with established system of sovereign credit ratings throughout recent decades, sovereign credit rating has been a quantified and comparable measurement of country risk, an indispensable factor in pricing assets in bond and stock markets for international portfolio investors, and thus plays a crucial role in flows of capital in global financial markets. However, mounting numbers of scholars have criticized rating agencies as the culprit of destabilizing global financial system. Ferri et al. [3] argue that adjustments of ratings announced by rating agencies have conspicuously followed business cycles. They upgrade ratings when countries maintain good momentum of economic growth and downgrade ratings when countries suffer economic downturns, which results in a boom to burst in stock markets and intensified fluctuations in financial markets. Kaminsky and Schmukler [4] have collected evidences of such pattern in their event studies in changes of credit ratings on developing countries.

On the other hand, changes of credit ratings might as well signify a wake-up call that triggers a spillover effect on other countries with unadjusted ratings. For example, by investigating impacts of rating adjustments on market premium of stock markets in unadjusted countries, Ferreira and Gama [5] display asymmetric effects of upgrade and downgrade rating events, and geographical proximity and whether countries belonging to developing countries have significant impacts on spillover effect. And how adjustments of sovereign credit ratings as a crucial signal influences the stability of global financial markets has been a hot debated topic among international finance academes. Kaminsky and Schmukler [4] construct a panel of stock markets in developing countries and discover that changes on sovereign credit ratings influence both stock market returns and country risk. Moreover those effects are transnational and are more pronounced to neighboring countries. Gande and Parsely [6] directly investigat effects of changes on ratings on sovereign credit spreads and find out that negative rating events abroad are associated with a significant increase in spread while no discernable effect of abroad positive rating events. Specifically, they distinguish between common information and differential components of spillovers. While 
unlike the Ferreira and Gama [5], they argue that cultural or institutional linkages, geographical proximity and rule of law traditions do not influence spillover effect. Reinhart [7] demonstrates that adjustment on credit ratings could be a decisive indicator of forecasting financial crisis. Given the frequent changes of ratings during financial crisis, studies in effects of ratings events on financial crisis have also been hot debated. For instance, Chiang et al. [8] find out that rating events during Asian financial crisis have caused structural impact on dynamic co-movement among Asian stock markets.

To sum up, major researches focus on effects of sovereign credit ratings events on risk premium on stock or bond markets, but fewer studies in their effects on financial interdependencies among different countries. However, international portfolio investors aim to take advantage of different correlations among financial markets in home countries and foreign countries to diversify systematic risks. Accordingly, effects of sovereign credit rating events on correlation among different countries should be the indispensable conference for international portfolio investors to allocate their assets. Among relative literature, Gande and Parsely [6] investigate cross-country correlation matrices of returns in negative rating events days and none-event days, and discover that correlation among different stock markets in downgrade event days has decreased significantly compared to that on none-event days, while Ferreira and Gama [5] offer an evidence of a significant increased correlation in negative rating event days. However, neither of two considers the time-varying features of correlation. Taking advantage of Dynamic Conditional Correlation Model proposed by Engle [9], Chiang et al. [8] calculate time-varying conditional correlations of nine Asian daily stock-return data from 1990 to 2003, and discovered that international sovereign credit agencies play a significant role in shaping structure of dynamic correlations in the Asian markets. By applying dynamic correlation model to stock and bond markets in developing countries with the respective regional markets in Asian-Pacific, European, Latin America and Middle East and Africa, Christopher et al. [10] discover that changes on ratings lead to asymmetric effects on correlations in stock and bond markets and discern a significant longterm effect but less significant short-run effect.

In conclusion, for international portfolio investors prefer to invest in respective regional markets to reduce asymmetric information and sovereign credit ratings events might as well breed more significant spillover effects among regional countries because of geographical and cultural proximity and belonging to developing countries, this paper investigates effects of ratings events on Hong Kong, Taiwan India, Indonesia, South Korea, Malaysia, Philippine and Thailand on intra-regional interdependence of stock markets. This paper applies the analysis of cross-country correlation matrices of returns in negative ratings events days and none-event days, but furtherly includes studies of positive ratings event days so as to reveal an asymmetric effect of ratings changes on return correlations. Secondly, we also introduce dynamic conditional correlations and apply an error correction model as Chiang et al. [8] and Christopher [10] have utilized 
to investigate structural changes on correlations in a more spanned investigated period from 1994.1.1 to 2013.11.1 ${ }^{1}$ caused by sovereign credit changes, and distinguish short-run and long-run effects. In terms of our contributions, firstly, the academic significance relies in our analysis of effects of both upgrade and downgrade sovereign credit ratings events on both static and dynamic crosscountry correlations of stock markets in Asian emerging markets and our sample period is more spanned that previous researches. As for the practical and social significance, our empirical findings shed light on investors' decision of reallocating their portfolios in regional markets when credit rating events happen and regulators' management of shock to the stock markets caused by domestic as well as foreign rating events.

The rest of this paper is organized as follows. Section II outlines the data and model designed used in our analysis. Section III presents mainly empirical results, and I concluded this paper by summarizing major findings in section VI.

\section{Data and Model Design}

\subsection{Data and Variables}

\subsubsection{Stock Return Data}

Based on categorization of emerging markets in Asian Pacific area from Christopher et al. [10], we investigate stock markets in Hongkong, Taiwan, South Korea, Thailand, Indonesia, India and Philippine, and accordingly collect daily data of Hang Seng Index, Taiwan's TWSE Index, South Korea's KOSPI Index, Thailand's SET Index, Indonesia's Jakarta Composite Index (JCI), India's SENSEX30 Index, Philippine PSI Index and Malaysia's KLCI Index from 1994.1.5 to 2013. 11.15. All data is collected from Wind Database and has been calculated into logarithmic return, and we do not standardize the return. Considering differences in business days in different markets, we delete data in a day in which any markets were closed and finally gained 3989 daily return observations for each market. Thereafter, we calculate respective regional indices returns as an equal weighted average of seven index returns. Statistical description of index returns is listed in Table 1, and plot of returns is presented in Figure 1, all of which and following empirical statistics and figures are obtained by MATLAB programming.

From Figure 1, all indices present discernable characteristics of volatility clustering, which provide basis for utilizing DCC-GARCH model to calculate dynamic correlation of returns. In addition, compared to returns of other emerging stock markets, returns of Thailand are clustered more condensed and volatility is extremely high in the period of Asian financial crisis.

\subsubsection{Sovereign Ratings Variables}

We choose S \& P Foreign Currency Long Term Rating to construct sovereign rating variable, and its readiness is as follows. Firstly, Kaminsky and Schimukle

${ }^{1}$ Investigation period is majorly determined by the data availability. By contacting with Suk-Joong Kim, I have acquired sovereign credit ratings information (but no credit outlook information) of 77 countries (our target countries are included). 
Table 1. Summary descriptions of stock market index returns.

\begin{tabular}{cccccccc}
\hline & Mean & Max & Min & Variance & Kurtosis & Skewness \\
\cline { 2 - 7 } & HSI (Hong Kong) & $0.0004 \%$ & $5.8225 \%$ & $-3.9512 \%$ & 0.0072 & 7.7065 & -0.0268 \\
JCI (Indonesia) & $0.0133 \%$ & $4.9904 \%$ & $-5.5294 \%$ & 0.0069 & 10.5388 & -0.2666 \\
SENSEX 30 (India) & $0.0027 \%$ & $6.9444 \%$ & $-5.1287 \%$ & 0.0070 & 8.8748 & -0.0039 \\
KOSPI(South & $-0.0015 \%$ & $3.5444 \%$ & $-5.3711 \%$ & 0.0077 & 6.7142 & -0.3291 \\
Korea) & & & & & & & \\
KLCI (Malaysia) & $-0.0059 \%$ & $8.7986 \%$ & $-10.4897 \%$ & 0.0062 & 48.0950 & -0.2277 \\
PSI (Philippine) & $0.0022 \%$ & $7.0258 \%$ & $-4.2318 \%$ & 0.0064 & 12.9464 & 0.3160 \\
SET (Thailand) & $-0.0093 \%$ & $4.5935 \%$ & $-6.9762 \%$ & 0.0072 & 9.5131 & -0.0925 \\
Regional Index & $0.0003 \%$ & $2.8455 \%$ & $-3.4443 \%$ & 0.0045 & 8.4611 & -0.4225 \\
\hline
\end{tabular}
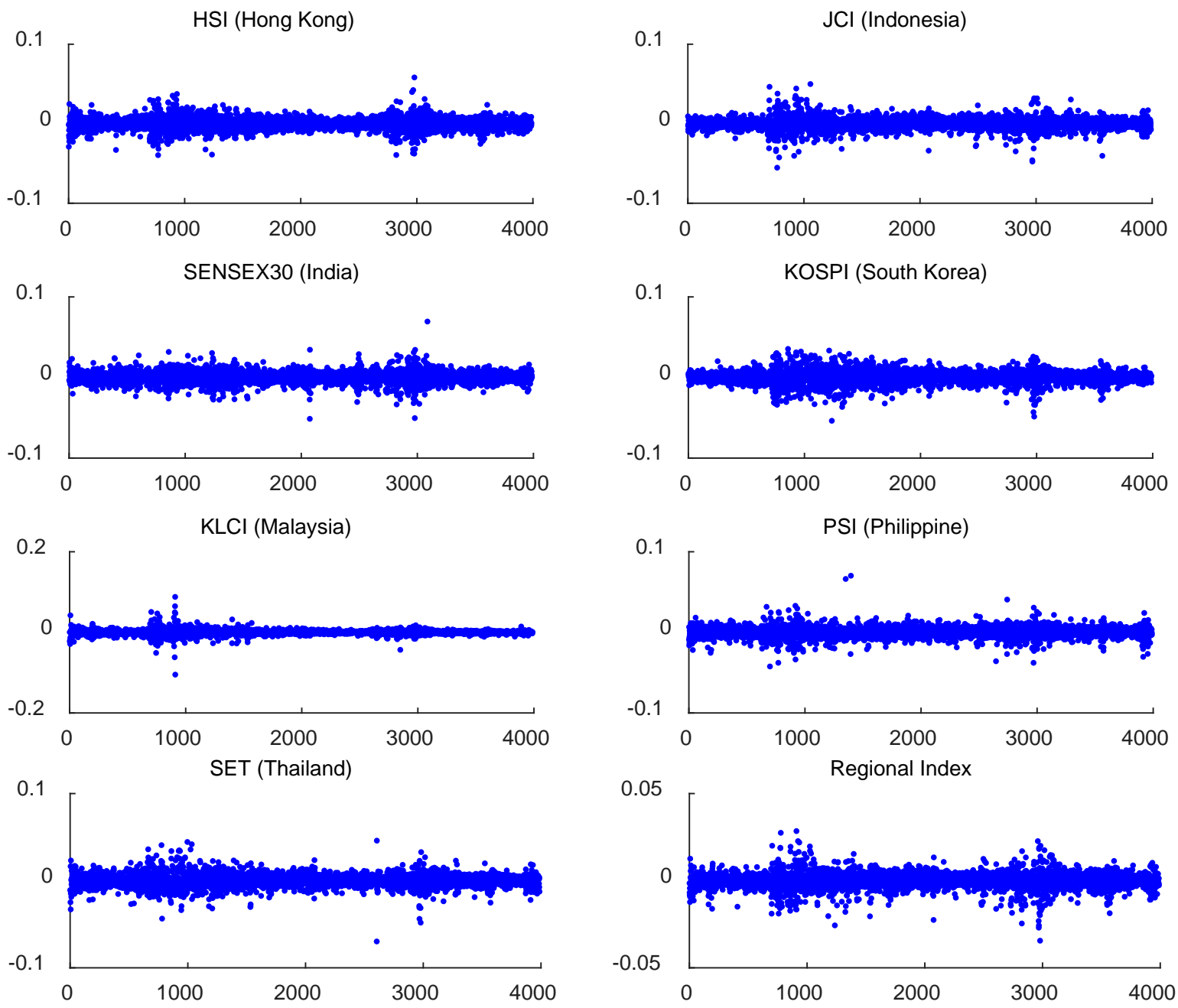

Figure 1. Daily returns of stock market index.

[4] and Brooks et al. [11] both point out that S \& P adjusts ratings more frequently and their adjustments always lead to other credit rating agencies to adjust rating. Secondly, Reisen and von Maltzan [12] and Brooks et al. [11] argue that rating events from S \& $\mathrm{P}$ are less expected by markets so as to generate a lager shock to stock markets. Finally, although S \& $\mathrm{P}$ sovereign rating also in- 
cludes Local Currency Long Term Rating and Credit Outlook, given data availabilities, we only focus on Foreign Currency Long Term Rating. Rating time series are gathered from Suk-Joong Kim who applies a linear rating transformation proposed by Ferreira and Gama [5] to Foreign Currency Long Term Ratings of 77 countries from 1994.1.1 to 2013.11.15. For this linear transformation, ratings ranks from SD/D up to AAA and accordingly counted from 0 to 20 with an interval of 1 . Accordingly, by a first differentiation of rating time series, we define the day of none-zero difference as rating event day. If the difference is positive, it is an upgrade rating event; if the difference is negative, it is a downgrade rating event. Our interested rating events of seven Asian emerging markets from 1994.1.5 to 2013.11.15 are listed in Table 2.

As Table 2 displays, there are 38 upgrade rating events and 25 downgrade rating events in our sample. Specifically, there are two dates in which two countries are simultaneously upgraded and one date in which three countries are simultaneously upgraded; for downgrade ratings, there are two dates in which two countries are downgraded. Noticeably, S \& P downgrade rating of Indonesia from CCC+ to SD/D while immediately upgrade from SD/D to CCC+. Concerning pervious deletion of data on dates in which any market was closed might also delete some rating events, in the following analysis, we regard the date which is most near to the possible deleted event days as rating events date.

\subsection{Model Design}

\subsubsection{Differences in Correlation Matrices on Rating Event and None Event Days}

In line with Gande and Parsely [6] and Ferreira and Gama [5], we are interested to test the differences in cross-country correlation matrices of rating event days and none event days, and if differences actually exist, we also long for discerning the directions of changes. In addition to investigation towards negative rating events as they have covered, we also study the effect of positive rating events. Our test generally includes following procedures.

Firstly, we open a window of $[-60,-21]$ with respect to positive (negative) rating event date for any country and randomly chose one trading return from seven countries and form a $7 \times 38(7 \times 25)$ return matrix for none event dates, and then calculate relative correlation matrices before positive (negative) ratings events. Above procedure will be repeatedly conducted for 10000 times and finally we obtain 10000 correlation matrices for none event days with respect to either positive or negative rating event dates. Thereafter, we implement following two tests.

Firstly, in order to discern the difference in correlation matrices of ratings event and none rating event date, we apply Jennrich [13] test.

Secondly, in terms of whether correlations increase or decrease on rating event date, we compare correlation coefficients in correlation matrices in each randomization to that of ranting event dates, and count the number of correlations on none events dates above or below those on rating event dates, and calculate net-increase proportion and net-decline proportion. And the comparison 
Table $2^{2}$. Summary descriptions of sovereign ratings events (1994.1.5-2013.11.15).

\begin{tabular}{|c|c|c|c|c|c|c|}
\hline \multirow[b]{2}{*}{ Markets } & \multicolumn{2}{|c|}{ Upgrade } & \multicolumn{4}{|c|}{ Downgrade } \\
\hline & Event Date & $\begin{array}{c}\text { Changes on } \\
\text { Ratings }\end{array}$ & Total & Event Date & $\begin{array}{c}\text { Changes on } \\
\text { Ratings }\end{array}$ & Total \\
\hline \multirow[t]{6}{*}{$\begin{array}{l}\text { Hong Kong } \\
(16.91)\end{array}$} & $1997 / 5 / 14$ & +1 & \multirow{6}{*}{5} & 1998/8/31 & -1 & \multirow{6}{*}{1} \\
\hline & $2001 / 2 / 9$ & +1 & & & & \\
\hline & $2005 / 7 / 20$ & +1 & & & & \\
\hline & $2006 / 7 / 27$ & +1 & & & & \\
\hline & $2008 / 7 / 31$ & +1 & & & & \\
\hline & $2010 / 12 / 16$ & +1 & & & & \\
\hline \multirow[t]{2}{*}{ India (10.02) } & $2005 / 2 / 2$ & +1 & \multirow{2}{*}{2} & $1998 / 10 / 22$ & -1 & \multirow{2}{*}{1} \\
\hline & $2007 / 1 / 30$ & +1 & & & & \\
\hline \multirow[t]{11}{*}{ Indonesia (7.50) } & $1995 / 4 / 18$ & +1 & \multirow{11}{*}{10} & $1997 / 10 / 10$ & -1 & \multirow{11}{*}{11} \\
\hline & $1999 / 3 / 30$ & +4 & & $1997 / 12 / 31$ & -1 & \\
\hline & $2000 / 10 / 10$ & +5 & & $1998 / 1 / 9$ & -1 & \\
\hline & $2002 / 9 / 5$ & +4 & & $1998 / 1 / 27$ & -3 & \\
\hline & $2003 / 5 / 12$ & +1 & & $1998 / 3 / 11$ & -1 & \\
\hline & $2003 / 10 / 8$ & +1 & & $1998 / 5 / 15$ & -1 & \\
\hline & $2004 / 12 / 22$ & +1 & & $1999 / 3 / 29$ & -4 & \\
\hline & $2006 / 7 / 26$ & +1 & & $2000 / 4 / 17$ & -4 & \\
\hline & $2010 / 4 / 23$ & +1 & & $2001 / 5 / 21$ & -1 & \\
\hline & $2011 / 4 / 8$ & +1 & & $2001 / 11 / 2$ & -1 & \\
\hline & & & & $2002 / 4 / 23$ & -3 & \\
\hline \multirow{8}{*}{$\begin{array}{c}\text { South } \\
\text { Korea }(14.36)\end{array}$} & $1995 / 5 / 3$ & +1 & \multirow{8}{*}{8} & $1997 / 10 / 24$ & -1 & \multirow{8}{*}{4} \\
\hline & $1998 / 2 / 18$ & +3 & & $1997 / 11 / 25$ & -2 & \\
\hline & $1999 / 1 / 25$ & +1 & & $1997 / 12 / 11$ & -3 & \\
\hline & $1999 / 11 / 11$ & +1 & & $1997 / 12 / 22$ & -4 & \\
\hline & $2001 / 11 / 13$ & +1 & & & & \\
\hline & $2002 / 7 / 24$ & +1 & & & & \\
\hline & $2005 / 7 / 27$ & +1 & & & & \\
\hline & $2012 / 9 / 14$ & +1 & & & & \\
\hline \multirow[t]{4}{*}{$\begin{array}{c}\text { Malaysia } \\
(13.78)\end{array}$} & $1994 / 12 / 29$ & +2 & \multirow{4}{*}{4} & $1997 / 12 / 23$ & -1 & \multirow{4}{*}{4} \\
\hline & $1999 / 11 / 10$ & +1 & & $1998 / 4 / 17$ & -1 & \\
\hline & $2002 / 8 / 20$ & +1 & & $1998 / 7 / 24$ & -1 & \\
\hline & $2003 / 10 / 8$ & +1 & & $1998 / 9 / 15$ & -2 & \\
\hline \multirow[t]{6}{*}{ Philippine (9.05) } & $1995 / 5 / 30$ & +1 & \multirow{5}{*}{5} & $2003 / 4 / 24$ & -1 & \multirow{5}{*}{2} \\
\hline & $1997 / 2 / 21$ & +1 & & $2005 / 1 / 17$ & -1 & \\
\hline & $2010 / 11 / 12$ & +1 & & & & \\
\hline & $2012 / 7 / 4$ & +1 & & & & \\
\hline & $2013 / 5 / 2$ & +1 & & & & \\
\hline & $1994 / 12 / 29$ & +1 & \multirow{3}{*}{3} & $1997 / 9 / 3$ & -1 & \multirow{3}{*}{3} \\
\hline \multirow[t]{2}{*}{ Thailand (12.66) } & $2003 / 10 / 8$ & +1 & & $1997 / 10 / 24$ & -2 & \\
\hline & $2004 / 8 / 26$ & +1 & & $1998 / 1 / 8$ & -1 & \\
\hline Total & & & 38 & & & 25 \\
\hline
\end{tabular}

${ }^{2}$ The number in the bracket after the name of a country represents the average numerical foreign currency rating level for the sample period and it ranges from 20 for AAA to 0 for SD/D. 
of those two proportions will shed lights on distinguishing the direction of changes in correlations on rating event dates.

\subsubsection{Two Tests Based on Dynamic Conditional Correlation}

\section{Model of Calculating Dynamic Conditional Correlation}

Engle [9] originally proposes three steps estimation of multivariable GARCH model to calculate dynamic conditional correlation. Accordingly, we apply two variables GARCH $(1,1)$ model (we call it DCC-GARCH model in the rest of paper) to calculate the time-varying correlations between each stock market index and regional market index, thereby conducting following regression analysis. There are two merits in applying DCC-GARCH model: firstly, it calculates correlations based on residuals which concerning the heteroscedasticity; secondly, in setting up the mean equations, it allows us to include other variables such as US stock returns which represents conditions of global stock markets. Our model is as follows:

$$
\begin{gathered}
r_{i, t}=\alpha_{i}+\beta_{i} r_{\mathrm{t}-1}^{\mathrm{US}}+e_{i, t} \\
r_{j, t}=\alpha_{j}+\beta_{j} r_{t-1}^{\mathrm{US}}+e_{j, t} \\
\boldsymbol{e}_{t}=\left(\begin{array}{l}
e_{i, t} \\
e_{j, t}
\end{array}\right) \sim N\left(o, \boldsymbol{H}_{t}\right) \quad \boldsymbol{H}_{t}=\left[\begin{array}{ll}
h_{i i, t} & h_{i j, t} \\
h_{j i, t} & h_{j j, t}
\end{array}\right]
\end{gathered}
$$

in which $r_{i, t}$ is daily return of each stock market index, $r_{j, t}$ is the daily return of regional market index. This model is formulated according to Christopher et al. [10] and we also include $r_{t-1}^{\mathrm{US}}$, the lagged daily returns of S\&P index in themean Equation (1), (2) as Chiang et al. [8] did in their analysis. With an OLS estimation of Equations (1) and (2), we obtained residual series $e_{i, t}$ and $e_{j, t}$, and assumed that they have a normal distribution with a mean of 0 and covariance matrix $\boldsymbol{H}_{t}$. GARCH $(1,1)$ requires elements in $\boldsymbol{H}_{t}$ subject to the following specification:

$$
\begin{gathered}
h_{i i, t}=\gamma_{0, i i}+\gamma_{1, i i} e_{i i, t-1}^{2}+\gamma_{2, i i} h_{i i, t-1} \\
h_{j j, t}=\gamma_{0, j j}+\gamma_{1, j j} e_{j j, t-1}^{2}+\gamma_{2, j j} h_{j j, t-1} \\
h_{i j, t}=\gamma_{0, i j}+\gamma_{1, i j} e_{i j, t-1}^{2}+\gamma_{2, i j} h_{i j, t-1}
\end{gathered}
$$

And the time-varying conditional correlations are calculated as below.

$$
\rho_{i j, t}=\frac{h_{i j, t}}{\sqrt{h_{i i, t} h_{j j, t}}}
$$

Summary of description of time-varying conditional correlations between 7 emerging stock markets and regional markets is listed in Table 3, and Figure 2 displays the trend of time-varying conditional correlations in our sample period.

Effects of Sovereign Rating Events on Dynamic Conditional Correlation

As public signals, will changes on sovereign ratings influence decisions of international portfolio investors so as to trigger a structural change on interdependences of stock markets in Asian Pacific area? In order to answer this question, we formulate indicate variables proposed by Chiang et al. [8] to measure 
Table 3. Summary of description of time-varying conditional correlations.

\begin{tabular}{ccccccc}
\hline & Mean & Max & Min & Variance & Kurtosis & Skewness \\
\hline HSI (Hong Kong) & 0.6800 & 0.8693 & 0.2632 & 0.1048 & 3.4943 & -0.6862 \\
JCI (Indonesia) & 0.6358 & 0.9026 & 0.1981 & 0.1283 & 3.0571 & -0.6913 \\
SENSEX30 (India) & 0.5575 & 0.7413 & -0.1485 & 0.1293 & 8.0836 & -1.7157 \\
KOSPI (South Korea) & 0.6058 & 0.8129 & -0.2248 & 0.1339 & 7.0901 & -1.5040 \\
KLCI (Malaysia) & 0.5436 & 0.8714 & 0.1099 & 0.1106 & 2.9025 & -0.1233 \\
PSI (Philippine) & 0.5010 & 0.7132 & 0.2459 & 0.0629 & 2.9814 & -0.2282 \\
SET (Thailand) & 0.6335 & 0.8626 & 0.2196 & 0.0788 & 4.0060 & -0.6007 \\
\hline
\end{tabular}

Time-Varying Conditional Correlations of Stock Market Index
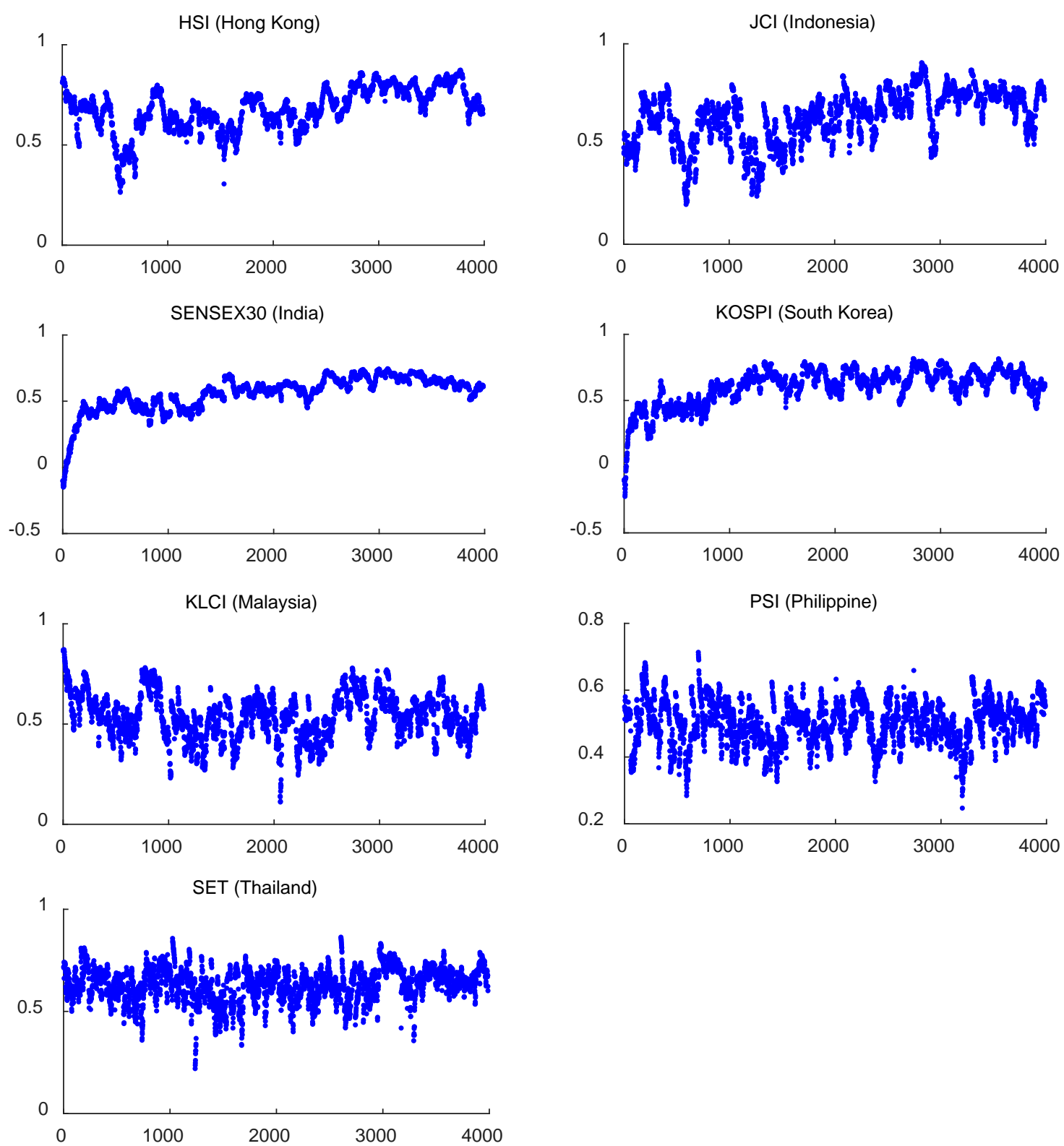

Figure 2. Time-varying conditional correlations of stock market index. 
the upgrade and downgrade rating events and indicate variables which display ratings change events in other countries in this region.

Firstly, for each country $i$, we open a window at time $T$ as $T_{s}=\{T-s, T, T+s\}$, and $s=\{-1,0,1\}$, we define $I_{i}^{(T s)}$ given by Equation (4) as a indicate function measuring changes on ratings, in which $\Delta v$ is the difference values that mentioned previously.

$$
I_{i}^{(T s)}=\left\{\begin{array}{l}
\Delta v,\left(t=T_{s}\right) \\
0,\left(t \neq T_{s}\right)
\end{array}\right.
$$

According to the sign of the value of $\Delta v$, we can distinguish a upgrade indicate variable $I_{i}^{(T s) \text { upgrade }}$ and downgrade indicate variable $I_{i}^{(T s) \text { downgrade }}$ as follows; and we assign an absolute value on $I_{i t}^{(T s)}$ for convenience of discussing marginal effect of negative ratings events on dynamic condition correlations.

$$
\begin{aligned}
I_{i t}^{(T s) u p g r a d e} & = \begin{cases}\left|I_{i t}^{(T S)}\right|, & I_{i t}^{(T s)}>0, \\
0, & I_{i t}^{(T s)} \leq 0\end{cases} \\
I_{i t}^{(T s) \text { downgrade }} & = \begin{cases}\left|I_{i t}^{(T s)}\right|, & I_{i t}^{(T s)}<0, \\
0, & I_{i t}^{(T S)} \geq 0\end{cases}
\end{aligned}
$$

Considering possible impacts of abroad rating events on dynamic conditional correlations, we additionally formulate $I_{\text {region }, t}^{(T s) \text { uprade }}, I_{\text {region }, t}^{(T s) \text { dongrade }}$ given by Equation of (7) and (8).

$$
\begin{gathered}
I_{\text {region }, t}^{(T s) \text { uprade }}=\sum_{i=1}^{7} I_{i t}^{(T s) \text { upgrade }}-I_{i t}^{(T s) \text { upgrade }} \\
I_{\text {regsion }, t}^{(T S \text { dorade }}=\sum_{i=1}^{7} I_{i t}^{(T s) \text { downgrade }}-I_{i t}^{(T s) \text { downgrade }}
\end{gathered}
$$

Finally we estimate marginal effect of rating events on dynamic conditional correlations by an OLS regression specified as Equation (9), and estimated coefficients $\beta_{1, i}\left(\beta_{2, i}\right)$ displays marginal effects of upgrade (downgrade) rating events, if $\beta_{1, i}>0\left(\beta_{2, i}>0\right)$,it shows that upgrade (downgrade) rating will increase the dynamic conditional correlation; if $\beta_{1, i}<0 \quad\left(\beta_{2, i}<0\right)$, it means that upgrade (downgrade) ratings will decrease crease the dynamic conditional correlation. Similarly, $\gamma_{1, i}\left(\gamma_{2, i}\right)$ estimates marginal effect of foreign rating events in this region on dynamic conditional events, if $\gamma_{1, i}>0\left(\gamma_{2, i}<0\right)$, it means foreign upgrade (downgrade) rating will increase the dynamic conditional correlation; while if $\gamma_{1, i}>0\left(\gamma_{2, i}<0\right)$, it means foreign upgrade (downgrade) rating will decrease the dynamic conditional correlation.

$$
\rho_{i j, t}=\alpha+\beta_{1, i} I_{i, t}^{(T s) \text { upgrade }}+\beta_{2, i} I_{i, t}^{(T s) \text { downgrade }}+\gamma_{1, i} I_{\text {region }, t}^{(T s) \text { upgrade }}+\gamma_{2, i} I_{\text {region }, t}^{(T s) \text { downgrade }}+\varepsilon_{i j}
$$

\section{Short-and long-term effect of Sovereign Ratings on Dynamic Conditional}

\section{Correlation}

Although previous discussion on marginal effect of indicate variables that measure rating events sheds light on whether sovereign ratings events cause a structural change on interdependence of stock markets, it fails to discern whether such effect is transitory (short-term effect) or permanent (long-term effect). Similar to Christopher et al. [10], we apply an Error Correction Model specified by Equation (10) to distinguish between transitory and permanent effects. 


$$
\begin{aligned}
& \rho_{i j, t}=\alpha_{0 i}+\alpha_{1 i} \text { Rating }_{i, t}+\varepsilon_{i, t} \\
& \Delta \rho_{i j, t}=\beta_{0, i}+\beta_{1, i} \Delta \text { Rating }_{i, t}+\beta_{2, i} \varepsilon_{i, t-1}+\beta_{3, i} \operatorname{VIX}_{t}+u_{i, t}
\end{aligned}
$$

In this model Rating ${ }_{i, t}$ is time series of Foreign Currency Long Term Ratings of country $i$, VIX $t$ is the Volatility Index of S \& P 500 Index provided by Chicago Board of Option Exchange. Different from Christopher et al. [10], we do not introduce volatility of exchange rates ${ }^{3}$ and only include VIX of S\&P 500 In$\mathrm{dex}^{4}$ as a control variable. For VIX of S \& P 500 Index measures the risk aversion of international portfolio investors, we predict that the coefficient should be positive.

Gande and Parsely [6] argue that spillover effects of rating events could be transferred by either common information effect or differential component effect, thus estimated $\alpha_{1}$ discerning long-term permanent effect and $\beta_{1}$ discerning short-term transitory effect could be either positive or negative. If estimated coefficients are positive, it indicates that upgrade (downgrade) rating will increase (decrease) stock market co-movements with the respective regional stock index. In details, for upgrade rating events, common information effect dominates. Upgraded rating of one country not only indicates economic improvement of upgraded country but also signifies growth in other regional countries, thus boosted investment in upgraded countries also encourages investment in neighboring countries. On the contrary, investors regard downgrade event as a specific risk factor of downgraded countries so as to reduce the stock market co-movements with respective regional stock index. If the estimated coefficients are negative, upgrade (downgrade) events will decrease (increase) stock market co-movements. Investors treat upgrade rating events as the distinct signal of improved economic and investment conditions and encourage capital flows withdraw from neighboring countries to upgraded countries so as to decrease correlations. In contrast, downgrade events breed financial contagion effect, which discourage investors to withdraw their capitals from the whole regions, thereby intensifying stock market co-movements in this region.

\section{Empirical Results}

\subsection{Differences in Correlation Matrices on Ratings Events and None Events Days}

Applying Jennrichchi-square test for the equality of correlation matrix on none-event days and event days in each random selection, we obtain 10000 chisquare test statistics. With a threshold value of 32.67 for the significance at the level $5 \%$ under the degree of freedom of 21 , we apply a right tail test of the mean and median of Jennrich chi-square statistics and relative $t$ statistic and $z$ statistic are listed in the Table 4.

${ }^{3}$ Due to the large quantities of missing values of exchange rate of Indonesia Rupiah to U.S dollars and unavailability of high frequent intra-day data of exchange rates, we could not apply GARCH model or utilize intra-day dates to calculate daylily volatility of exchange rate.

${ }^{4}$ Christopher et al. [10] introduced VIX of each country as the measurement of uncertainty of financial markets. Given the unavailability of date, we only introduce VIX of S\&P as indicators of uncertainty of financial markets. 
From Table 4, both mean and median test demonstrate that correlations matrix on none-event days are significantly different from that on upgrade rating event days or downgrade rating days, and the difference is significant at the $1 \%$ level. Consistent with Gande and Parsely [6], we reveal that the correlation of stock markets on none event days is highly different from that on downgrade rating event days. Moreover, we also find out that such difference exists for the upgrade rating event and the significance level is even higher than that of downgrade rating event.

Furthermore, Table 5 gives us clues on the directions of changes on correlations from none-event days to event days. Firstly, for downgrade rating events, net-increase proportion is conspicuously higher than net-decrease proportion, which is similar to Ferreira and Gama [5]. That is to say, when downgrade rating events happen, correlation of stock markets with respective regional markets is inclined to increase rather than decrease. Interestingly, for upgrade rating events, the net-increase proportion also exceeds net-decrease proportion. Above test generally shows that investors tend to treat any rating event as not only a specific signal of change of sovereign risk for the adjusted country but common information for the whole regional market, so as to increase the correlation of stock markets in this region on the event days. However, when we compare the difference of net-increase proportion and net-decrease proportion when upgrade rating happens to that when downgrade rating happens, we find out that decrease of correlation happens more frequently when downgrade rating happens. That is to say, compared to upgrade rating events, downgrade rating events are more likely to be regarded as specific change of risk factors for the adjusted country, so as to decrease the correlation of stock markets in this region.

Above analysis displays that correlation of stock markets in regional market changes significantly on the day of rating adjustments. While such analysis on

Table 4. Right tail test of the mean and median of Jennrich chi-square statistics.

\begin{tabular}{ccc}
\hline & Mean Test & \\
\hline Tstatistics & Upgrade Rating & Downgrade Rating \\
& $283.90^{* * *}$ & $38.25^{* * *}$ \\
\hline$Z$ statistics & Median Test & Downgrade Rating \\
\hline
\end{tabular}

${ }^{* * *}$ denote significance at the $1 \%$ level.

Table 5. Changes on correlations from none-vent days to event days.

\begin{tabular}{ccc}
\hline & Upgrade Rating & Downgrade Rating \\
\hline Net-increase proportion & $93.50 \%$ & $79.43 \%$ \\
Net-decrease proportion & $6.50 \%$ & $20.57 \%$ \\
\hline
\end{tabular}


the static correlation fails to enlighten us whether rating adjustment could impose structural changes on correlation and whether such effect is permanent or transitory. Those questions will be disentangled by empirical results based on the dynamic conditional correlation of stock markets with respective of regional markets in the following section.

\subsection{Emprical Results of Two Tests Based on Dynamic Conditional Correlation}

\subsubsection{Effects of Sovereign Rating Events on Dynamic Conditional Correlation}

Table 6 listed OLS estimated coefficients and $t$ statistics of Equation (9), and all $t$ statistics has been adjusted by New-West method with lagged one term.

Firstly, coefficient of $I_{i}^{(T s) \text { downgrade }}$ is significant at the $1 \%$ level in all models, which implies that when rating of one country is downgraded its correlation of stock market index with respective regional market index has been changed significantly. While coefficient of $I_{i}^{(T s) u p g r a d e}$ is only significant at the $1 \%$ level for Indonesia and at the $10 \%$ level for India and South Korea.Furthermore, if we only consider the coefficient of $I_{i}^{(T s) \text { upgrade }}$ which is significant at the level $1 \%$, we find out that the upgrade rating event increases the correlations of stock market index in Indonesia with respective regional market index.

Table 6. Regression results of sovereign rating events on dynamic conditional correlation.

\begin{tabular}{|c|c|c|c|c|c|}
\hline$\rho_{i j, t}$ & $I_{i}^{(T S) \text { upgrade }}$ & $I_{i}^{(T s) d o w n g r a d e}$ & $I_{i, \text { region }}^{(T S \text { upgrade }}$ & $I_{i, \text { region }}^{(T S) \text { downgrade }}$ & constant \\
\hline HSI & -0.0328 & $-0.0815^{* * *}$ & -0.0017 & $0.0220^{* * *}$ & $0.6806^{* * *}$ \\
\hline (Hong Kong) & $(-0.7386)$ & $(-20.7841)$ & $(-0.4031)$ & $(4.4826)$ & $(287.8014)$ \\
\hline JCI & $0.0255^{* * *}$ & $-0.0356^{* * *}$ & -0.0039 & $0.0191^{* *}$ & $0.6363^{* * *}$ \\
\hline (Indonesia) & $(2.9833)$ & $(-11.9005)$ & $(-0.4995)$ & $(2.4598)$ & 219.8271 \\
\hline SENSEX30 & $0.0092^{*}$ & $0.0369^{* * *}$ & $-0.0199^{*}$ & $0.0383^{* * *}$ & $0.5586^{* *}$ \\
\hline (India) & $(1.7684)$ & $(5.8993)$ & $(-1.6912)$ & $(6.7488)$ & (190.8986) \\
\hline KOSPI & $-0.0407^{*}$ & $0.0459^{* * *}$ & 0.0105 & $0.0166^{*}$ & $0.6064^{* * *}$ \\
\hline (South Korea) & $(-1.6707)$ & $(3.8326)$ & $(0.9598)$ & $(1.6591)$ & $(201.6000)$ \\
\hline KLCI & 0.0300 & $-0.1121^{* * *}$ & $-0.0230^{*}$ & -0.0039 & $0.5437^{* * *}$ \\
\hline (Malaysia) & $(1.1222)$ & $(-5.4777)$ & $(-1.8713)$ & $(-0.2538)$ & $(220.8740)$ \\
\hline PSI & -0.0180 & $-0.0857^{* * *}$ & -0.0007 & 0.0000 & $0.5009^{* * *}$ \\
\hline (Philippine) & $(-0.6440)$ & $(-6.9142)$ & $(-0.1000)$ & $(-0.0019)$ & $(358.4257)$ \\
\hline SET & -0.0493 & $0.0384^{* * *}$ & 0.0036 & -0.0012 & $0.6336^{* * *}$ \\
\hline (Thailand) & $(-1.4581)$ & $(5.9414)$ & $(0.7583)$ & $(-0.2293)$ & $(361.6326)$ \\
\hline
\end{tabular}

Note: This table displays OLS regression results of, $\rho_{i j, t}=\alpha+\beta_{1, i} I_{i, t}^{(T) \text { upgrade }}+\beta_{2, i} I_{i, t}^{(T s) d o w n g r a d e}+\gamma_{1, i} I_{\text {region }, t}^{(T s)}+\gamma_{2, i} I_{\text {region, }, t}^{(T s) \text { downde }}+\varepsilon_{i j}$ is the dynamic conditional correlation of return of stock market index of country $i$ with respective of that of regional market index, $I_{i}^{(T s) \text { upgrade }} \quad\left(I_{i}^{(T S) d o w n g r a d e}\right)$ is the indication variables defining the upgrade (downgrade) rating event of country $i ; I_{i, \text { region }}^{(T \text { ) }}$ (d) $\quad\left(I_{i, \text { region }}^{(T) \text { downade }}\right)$ is the indication variable denoting foreign upgrade (downgrade) rating events in this region for country $i$. All $\mathrm{t}$ statistics in the parentheses below the coefficients are adjusted by New-West estimation with one lagged term. ${ }^{\star * *},{ }^{\star *}$, ${ }^{*}$ enote significance at $1 \%, 5 \%$ and $10 \%$ level. 
On the contrary, the sign of significant coefficients of $I_{i}^{(T S) \text { downgrade }}$ is complicated, indicating different spillover effects of rating events on stock markets co-movements. Four of seven significant coefficients are significantly negative, displaying a general effect of downgrade rating event decreasing stock markets co-movements in the Asian Pacific area. On other words, investors are inclined to regard downgrade rating events in this area as the specific information of risk of adjusted countries instead of a signal of the deteriorated economic and investment conditions of the whole regional markets. Consequently, international investors might withdraw capital from the downgraded country to the neighboring country so as to weaken the stock markets co-movement. While for the downgrade rating event of Thailand, positive coefficient of $I_{i}^{(T s) \text { downgrade }}$ demonstrates that co-movement of Thailand stock market with reginal market is intensified when negative rating event happens. For downgrade events of Thailand are clustered in the financial crisis in 1997 and the Thailand is the original source of this crisis, negative rating events trigger a financial contagion effect so as to deter the capital out of the regional markets, which intensify the co-movement of stock markets in this region.

In terms of the effect of neighboring rating events on stock markets co-movement, significance of estimated coefficient of $I_{i \text {,region }}^{(T S) \text { uprade }}$ and $I_{i, \text { region }}^{(T S) \text { downgade }}$ reveals that neighboring downgrade rating events are more likely to introduce structure changes on correlations of stock market index with respective of regional market index. In details, for neighboring upgrade rating events, only the correlations of Indonesia and Malaysia stock markets with respective of regional market index is significant, but the effect is only significant at the $10 \%$ level. While facing the neighboring downgrade rating events, co-movements with regional markets is significant positive at the level of $1 \%$ for Hong Kong and India stock markets, at the level of $5 \%$ for the Indonesia stock market and at the level of $10 \%$ for South Korea stock markets.

\subsubsection{Short- and Long-Term Effect of Sovereign Ratings on Dynamic Conditional Correlation}

Regression results of Error Correction Models in Table 7 gives us clues on whether sovereign rating impose short-or long-term effects on stock co-movements. Firstly, six of seven estimated $\alpha_{1}$ is significant at the $1 \%$ level, indicating a general long-term effect of sovereign ratings on stock markets co-movements, while $\beta_{1}$ indicating the short-term effect of sovereign rating is only significant for the correlation of Thailand stock markets with regional market.

More specifically, $\alpha_{1}$ in models of Hong Kong, Indonesia, Malaysia and Thailand is significantly positive and is positive in the model of Philippine though insignificant, but is negative in the Model of India and South Korea. Above results indicate, in general, when positive rating events happen, investors not only treasure it as a signal of the improvement of economic and investment condition of adjusted countries but an indicator of the uprising of the whole region so as to increase the investment in the whole region and promote comovement of stock markets; however, when a negative rating happen, investor 
prefer to regard it as a specific signal of deteriorated credit condition of adjusted country and reallocate weights of the international investment portfolio by withdrawing the capital from downgraded country to neighboring countries so as to weaken the co-movement of stock markets. Above findings in terms of long-term effect are consistent with Christopher et al. [10]. As for the significant negative $\alpha_{1}$ in the model of India and South Korea, we offer two possible explanations according to Ferreira and Gama's [5] interpretation of how geographical proximity and belonging to developing countries impact the spillover effect. Firstly, South Korea and India locate geographically far away from other five emerging markets, therefore international portfolio investors are inclined to treasure the upgrade rating event of those two countries as their idiosyncratic information. While as South Korea and India are fast-growing countries in this area, downgrade ratings of those two entities might be treated as the signal of the overall economic downturn in this region, thereby this common information spillover might condense co-movement of the stock markets in this region.

Table 7. ECM estimation results: Sovereign rating effects on stock market co-movements.

\begin{tabular}{cccccccc}
\hline & $\alpha_{0}$ & $\alpha_{1}$ & $\beta_{0}$ & $\beta_{1}$ & $\beta_{2}$ & $\beta_{3}$ & coint_test \\
\hline HSI & $0.0852^{* * *}$ & $0.0352^{* * *}$ & $-0.0012^{* * *}$ & 0.0025 & $-0.0128^{* * *}$ & $0.0001^{* *}$ \\
(Hong Kong) & $(4.8808)$ & $(35.7615)$ & $(-2.5819)$ & $(1.0858)$ & $(-3.3065)$ & $(2.5469)$ & $-4.8887^{* * *}$ \\
JCI & $-0.1326^{* * *}$ & $0.0767^{* * *}$ & $-0.0014^{*}$ & -0.0058 & $-0.0187^{* * *}$ & $0.0001^{*}$ & $-6.3073^{* * *}$ \\
(Indonesia) & $(-4.4583)$ & $(26.5222)$ & $(-1.7486)$ & $(-0.9252)$ & $(-5.3569)$ & $(1.8782)$ \\
SENSEX30 & $0.5890^{* * *}$ & $-0.0042^{* * *}$ & $-0.0007^{*}$ & 0.0005 & $-0.0063^{* * *}$ & $0.0000^{* * *}$ & $-5.0152^{* * *}$ \\
(India) & $(92.4974)$ & $(-4.4882)$ & $(-1.8440)$ & $(1.0156)$ & $(-4.7652)$ & $(2.2457)$ \\
KOSPI & $0.8689^{* * *}$ & $-0.0183^{* * *}$ & $-0.0014^{* *}$ & 0.0033 & $-0.0129^{* * *}$ & $0.0001^{* * *}$ & $-5.7283^{* * *}$ \\
(South Korea) & $(34.4788)$ & $(-10.2512)$ & $(-2.1282)$ & $(0.9855)$ & $(-5.2456)$ & $(2.6221)$ & $0.0002^{* * *}$ \\
KLCI & $0.2773^{* * *}$ & $0.0193^{* * *}$ & $-0.0033^{* * *}$ & -0.0040 & $-0.0293^{* * *}$ & $-7.5807^{* * *}$ \\
(Malaysia) & $(12.1227)$ & $(11.6152)$ & $(-3.5795)$ & $(-0.8991)$ & $(-6.9609)$ & $(3.5538)$ & -0.0000 \\
PSI & $0.4798^{* * *}$ & 0.0023 & 0.0004 & -0.0050 & $-0.0450^{* * *}$ & $-9.3198^{* * *}$ \\
(Philippine) & $(32.8765)$ & $(1.463)$ & -0.5715 & $(-0.4835)$ & $(-9.9864)$ & $(-0.5831)$ \\
SET & $0.5759^{* * *}$ & $0.0046^{* * *}$ & $-0.0034^{* * *}$ & $0.0251^{* * *}$ & $-0.0677^{* * *}$ & $0.0002^{* * *}$ & $-11.5384^{* * *}$ \\
(Thailand) & $(32.4591)$ & $(3.3268)$ & $(-3.2438)$ & $(4.4559)$ & $(-10.9694)$ & $(3.2778)$ \\
\hline
\end{tabular}

Note: This table regression result of Error Correction Model given by: $\begin{aligned} & \rho_{i, t, t}=\alpha_{0 i}+\alpha_{1 i} \operatorname{Rating}_{i, t}+\varepsilon_{i, t} \\ & \Delta \rho_{i, t, t}=\beta_{0, i}+\beta_{1, i} \Delta \operatorname{Rating}_{i, t}+\beta_{2, i} \varepsilon_{i, t-1}+\beta_{3, i} \mathrm{VIX}_{t}+u_{i, t}\end{aligned} \rho_{i, t, t}$ is the dynamic conditional correlation of return of stock market index of country i with respective of that of regional market index, Rating ${ }_{i, t}$ is the rating series of country I, VIX, is the Volatility Index of S\&P 500 Index provided by Chicago Board of Option Exchange. All $t$ statistics in the parentheses below the coefficients are adjusted by New-West estimation with one lagged term. coint_test is statistics of the CADF test in terms of $\rho_{i, t,}$ and Rating it, $_{\text {with lagged } 1 \text { term }}^{5}$, ***, **, *denote significance at $1 \%, 5 \%$ and $10 \%$ level.

${ }^{5}$ With ADF tests of $\rho_{i j, t}$, Rating $g_{i t}$ and VIX with 1 to 6 lagged terms, we found $\rho_{i j, t}$ follows an $I(0)$ process, which is significant at the $1 \%$ level, and Rating $g_{i t}$ is an non-stationary process, VIX $_{t}$ is stationary at the level $1 \%$ With CADF cointegration tests we found out $\rho_{i, t}$ and

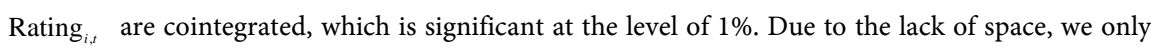
presents the cointegration results with respect of 1 lagged term. 
In terms of the short-term effect, estimated coefficient $\beta_{1}$ is only significant in the model of Thailand, and the significance is at $1 \%$ level. With a closer look on the adjustments of rating on Thailand, we find that all downgrade rating events happened during the Asian Crisis and upgrade rating events happened right after the crisis. As the trigger of the Asian Financial Crisis, downgrade rating event for Thailand triggers financial contagion in this area while upgrade rating event signifies economic condition of the whole region claw out of slump since the crisis, so as to increase the co-movement of stock markets. In addition, coefficient of VIX is positively significant as we expected. Increased VIX indicates that investors have higher risk aversion and prone to diversify their asset into neighboring markets when economic and investment condition is uprising in the home country, but withdraw the capital from the whole region when downgrade event happens.

\section{Conclusions}

This paper originally investigates how co-movements of stock market index with respective to regional market index react to both upgrade and downgrade sovereign credit rating events, and reveals that those effects are asymmetric in terms of both static and dynamic interdependence of stock markets in a fairly spanned sample period. Namely, we find out increases in correlations in both upgrade and downgrade rating day and the effect is more profound for upgrade rating events, but the frequency of decreasing correlations is significantly higher in downgrade rating days. As for asymmetric effects on dynamic correlations, we discover a significant increase in the correlations of most countries because of the common information effect triggered by the upgrade rating events, while for the downgrade rating events, dominant differential information effects result in decrease in the correlations. Moreover, we discern a significant long-run effect of sovereign credit rating on correlations, and correlations, similar to the previous test, increase because of common information effect when ratings are upgraded and decrease because of differential information effect when ratings are decreased.

Our original empirical findings demonstrates that, because of the existed asymmetric effects, both investors' decision of reallocating their portfolios in regional markets and regulators' management of shock to the stock markets caused by domestic as well as foreign rating events should be adjusted and tailed differently. However, due to data availability, we do not investigate the effect of credit outlook information which is argued by Christopher et al. [10] to impose a more significant spillover effect on co-movement of bond markets. Therefore, it is of necessities to incorporate information of credit outlook into changes on sovereign credit status and further investigate its asymmetric effect on bond market as well.

\section{References}

[1] Calvo, G. and Mendoza, E. (2000) Rational Contagion and the Globalization of Se- 
curities Market. Journal of International Economics, 51, 79-113. https://doi.org/10.1016/S0022-1996(99)00038-0

[2] Chan, K., Covrig, V. and Ng, L. (2005) What Determines the Domestic Bias and Foreign Bias? Evidence for Mutual Fund Equity Allocations Worldwide. Journal of Finance, 60, 1495-1534. https://doi.org/10.1111/j.1540-6261.2005.768_1.x

[3] Ferri, G., Liu, G. and Stiglitz, J. (1999) The Procyclical Role of Rating Agencies: Evidence from the East Asian Crisis. Economic Notes, 3, 335-355. https://doi.org/10.1111/1468-0300.00016

[4] Kaminsky, G. and Schmukler, S.L. (2002) Emerging Market Instability: Do Sovereign Ratings Affect Country Risk and Stock Returns? World Bank Economic Review, 16, 171-195. https://doi.org/10.1093/wber/16.2.171

[5] Ferreira, M.A. and Gama, P.M. (2007) Does Sovereign Debt Ratings News Spill over to International Stock Markets? Journal of Banking and Finance, 31, 3162-3182. https://doi.org/10.1016/j.jbankfin.2006.12.006

[6] Gande, A. and Parsley, D.C. (2005) News Spillovers in the Sovereign Debt Market. Journal of Financial Economics, 75, 691-734. https://doi.org/10.1016/j.jfineco.2003.11.003

[7] Reinhart, C. (2001) Do Sovereign Credit Ratings Anticipate Financial Crises? Evidence from Emerging Markets. University of Maryland, College Park.

[8] Chiang, T.C., Jeon, B.N. and Li, H. (2007) Dynamic Correlation Analysis of Financial Contagilon: Evidence from Asian Markets. Journal of International Money and Finance, 26, 1206-1228. https://doi.org/10.1016/j.jimonfin.2007.06.005

[9] Engle, R. (2002) Dynamic Conditional Correlation-A Simple Class of Multivariate GARCH Models. Journal of Business and Statistics, 20, 339-350. https://doi.org/10.1198/073500102288618487

[10] Christopher, R., Kim, S. and We, E. (2012) Do Sovereign Credit Ratings Influence Regional Stock and Bond Market Interdependencies in Emerging Countries? Journal of International Financial Markets, Institutions and Money, 22, 1070-1089. https://doi.org/10.1016/j.intfin.2012.01.003

[11] Brooks, R., Faff, R., Hillier, D. and Hillier, J. (2004) The National Market Impact of Sovereign Rating Changes. Journal of Banking and Finance, 28, 233-250. https://doi.org/10.1016/S0378-4266(02)00406-5

[12] Reisen, H. and von Maltzan, J. (1999) Boom and Bust and Sovereign Rating. Technical Paper No. 148, OECD. https://doi.org/10.1787/251521656447

[13] Jennrich, R. (1970) An Asymptotic Chi-Square Test for the Equality of Two Correlation Matrices. Journal of the American Statistical Association, 65, 904-912. 
Submit or recommend next manuscript to SCIRP and we will provide best service for you:

Accepting pre-submission inquiries through Email, Facebook, LinkedIn, Twitter, etc. A wide selection of journals (inclusive of 9 subjects, more than 200 journals)

Providing 24-hour high-quality service

User-friendly online submission system

Fair and swift peer-review system

Efficient typesetting and proofreading procedure

Display of the result of downloads and visits, as well as the number of cited articles Maximum dissemination of your research work

Submit your manuscript at: http://papersubmission.scirp.org/

Or contact me@scirp.org 